\title{
A novel technique for selective NF- $\kappa B$ inhibition in Kupffer cells: contrary effects in fulminant hepatitis and ischaemia-reperfusion
}

\author{
F Hoffmann, ${ }^{1,2}$ G Sass, ${ }^{3}$ J Zillies, ${ }^{1}$ S Zahler, ${ }^{1}$ G Tiegs, ${ }^{3}$ A Hartkorn, ${ }^{1}$ S Fuchs,,${ }^{1}$ J Wagner, ${ }^{4}$ \\ G Winter, ${ }^{1}$ C Coester, ${ }^{1}$ A L Gerbes, ${ }^{2}$ A M Vollmar ${ }^{1}$
}

\begin{abstract}
See Commentary, p 1580
${ }^{1}$ Department of Pharmacy, Center of Drug Research, University of Munich, Germany;

${ }^{2}$ Klinikum Großhadern,

University of Munich, Germany;

${ }^{3}$ Division of Experimental Immunology and Hepatology, University Medical Centre Hamburg Eppendorf, Hamburg, Germany; ${ }^{4}$ Institute of Pathology, University of Munich, Germany
\end{abstract}

Correspondence to:

Professor A M Vollmar,

Department of Pharmacy, Center of Drug Research,

Butenandtstrasse 5-13, D-81377

Munich, Germany; Angelika.

Vollmar@cup.uni-muenchen.de

Revised 2 February 2009 Accepted 19 March 2009

Published Online First

25 May 2009

\section{ABSTRACT}

Background and aims: The transcription factor nuclear factor kappa B (NF- $\mathrm{kB}$ ) has risen as a promising target for anti-inflammatory therapeutics. In the liver, however, NF$\kappa \mathrm{B}$ inhibition mediates both damaging and protective effects. The outcome is deemed to depend on the liver cell type addressed. Recent gene knock-out studies focused on the role of NF- $\kappa \mathrm{B}$ in hepatocytes, whereas the role of NF- $\kappa B$ in Kupffer cells has not yet been investigated in vivo. Here we present a novel approach, which may be suitable for clinical application, to selectively target NF- $\mathrm{KB}$ in Kupffer cells and analyse the effects in experimental models of liver injury.

Methods: NF- $\kappa B$ inhibiting decoy oligodeoxynucleotides were loaded upon gelatin nanoparticles (D-NPs) and their in vivo distribution was determined by confocal microscopy. Liver damage, NF- $\kappa B$ activity, cytokine levels and apoptotic protein expression were evaluated after lipopolysaccharide (LPS), D-galactosamine (GaIN)/LPS, or concanavalin A (ConA) challenge and partial warm ischaemia and subsequent reperfusion, respectively.

Results: D-NPs were selectively taken up by Kupffer cells and inhibited NF- $\mathrm{\kappa B}$ activation. Inhibition of NF- $\mathrm{kB}$ in Kupffer cells improved survival and reduced liver injury after GaIN/LPS as well as after ConA challenge. While anti-apoptotic protein expression in liver tissue was not reduced, pro-apoptotic players such as cJun $\mathrm{N}$-terminal kinase (JNK) were inhibited. In contrast, selective inhibition of NF-kB augmented reperfusion injury.

Conclusions: NF-кB inhibiting decoy oligodeoxynucleotide-loaded gelatin nanoparticles is a novel tool to selectively inhibit NF-kB activation in Kupffer cells in vivo. Thus, liver injury can be reduced in experimental fulminant hepatitis, but increased at ischaemia-reperfusion.

The redox-sensitive transcription factor nuclear factor kappa B (NF-kB) displays pleiotropic effects during inflammation, immune response, cell survival and proliferation and is a major target of novel drugs counteracting the inflammatory response. ${ }^{12}$ In the liver, however, NF- $\kappa B$ is thought to exhibit a dual role, depending on the cell type. Activation of $N F-\kappa B$ in the resident liver macrophages, ie, Kupffer cells (KCs), causes increased expression of proinflammatory cytokines leading to inflammation and liver failure. ${ }^{3}$ Induction of NF- $\kappa \mathrm{B}$ activity in hepatocytes, however, is linked to cellular protection by increasing the transcription of antiapoptotic genes. ${ }^{4}$ Most studies addressing this point have been performed with isolated liver cells in vitro.
Recent publications tried to shed some light on this issue in vivo. ${ }^{5-8}$ Since constitutive NF- $\mathrm{KB}$ knock-out mice die during embryogenesis, ${ }^{9}$ an approach guided by the creation of conditional knock-out animals was pursued. NF- $\mathrm{kB}$ is mainly activated upstream by a kinase complex containing the (catalytic) subunits I-kappaB kinase $\alpha$ (IKK $\alpha$ ), IKK $\beta$ and the regulatory protein NF- $\mathrm{\kappa B}$ essential modulator (NEMO). ${ }^{10}$ Hepatocyte-specific NEMO deletion leads to a complete inactivation of NF- $\kappa B$, which correlates with enhanced susceptibility to tumour necrosis factor $\alpha$ (TNF $\alpha$ ) stimulation, ischaemia-reperfusion injury ${ }^{5}$ and, finally, to cancer development. ${ }^{6}$ Hepatocyte-specific p65 knock-out mice are also more susceptible to TNF $\alpha$-induced liver damage. ${ }^{7}$ IKK $\beta$ knock-out in hepatocytes does not abolish NF-kB activation entirely, hence a protection of the parenchyma to a certain degree upon TNF $\alpha$ challenge still remains.

To our knowledge, conditional NF-kB knock-out mice for $\mathrm{KCs}$ are not available, and a genetic approach to inhibit NF-kB in KCs would not easily be suitable for clinical application. Moreover, adenoviral transfection of an I $\mathrm{KB}$ super-repressor is not limited to $\mathrm{KCs},{ }^{12}$ and liposomal targeting of the liver macrophages with NF- $\mathrm{BB}$ inhibiting decoy oligodeoxynucleotides cannot ensure an exclusive transport to KCs only. ${ }^{13}$

Therefore, aims of this study were (1) to develop a non-genetic approach to selectively abrogate NF$\kappa \mathrm{B}$ activation in KCs without interfering with NF$\kappa B$ activity in hepatocytes, and (2) to subsequently elucidate the role of NF- $\mathrm{KB}$ activation in KCs in different settings of hepatic inflammatory injury.

Here we report a novel Kupffer cell specific carrier based on gelatin nanoparticles (NPs), which enables selective delivery of NF- $\mathrm{KB}$ decoy oligodeoxynucleotides to KCs without affecting NF- $\mathrm{KB}$ in hepatocytes. NF- $\kappa \mathrm{B}$ decoy oligodeoxynucleotides are double-stranded oligonucleotides which lead to competitive cis-trans interactions between oligonucleotides and the transcription factor, thus preventing binding of $\mathrm{NF}-\mathrm{KB}$ to the designated DNA. ${ }^{14} 15$

In a model of D-galactosamine/lipopolysaccharide (GalN/LPS)-induced as well as concanavalin A (ConA)-induced hepatic failure, treatment with

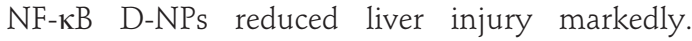
Interestingly, NF- $\mathrm{kB}$ activation in KCs seems to possess a different role in the setting of warm hepatic ischaemia-reperfusion injury, since here selective inhibition led to an increase of liver damage. 
Figure 1 Distribution of decoy oligonucleotide-loaded gelatin nanoparticles (D-NPs) in rat organs. (A) Rat organs (15 min after D-NP application) were sliced and stained. Red: Alexa Fluor 488 end-labelled nuclear factor kappa B (NF-кB) decoy oligonucleotides (ODNs). Blue: Hoechst staining of nuclei. Green: macrophage specific CD 163. Co-localisation of macrophages and NF- $\kappa$ B decoy ODNs are indicated by the yellow colour. (B) Analysis of liver sections. Red: Alexa Fluor 488 end-labelled NF-KB decoy ODNs. Green: Kupffer cells (KCs) specific CD 163. Blue: Hoechst staining of nuclei.

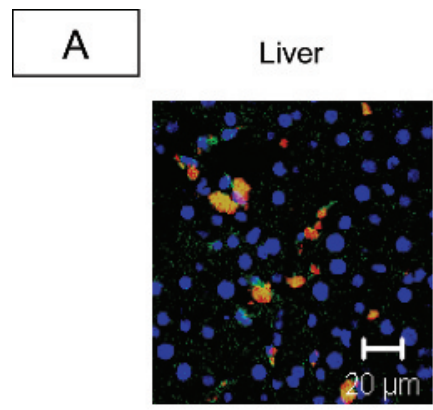

Kidney

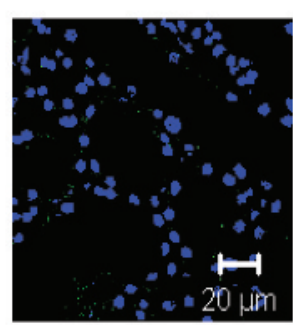

Lung

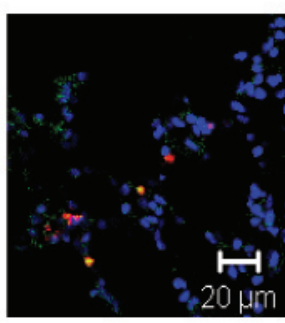

Brain

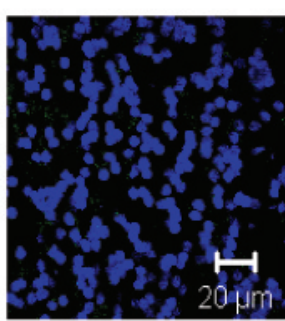

Spleen

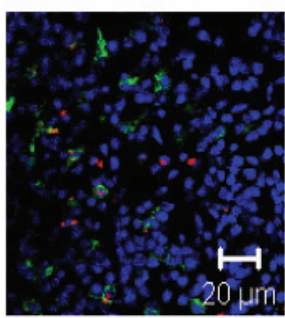

Heart

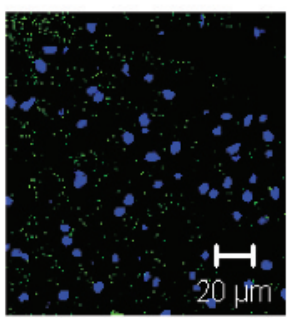

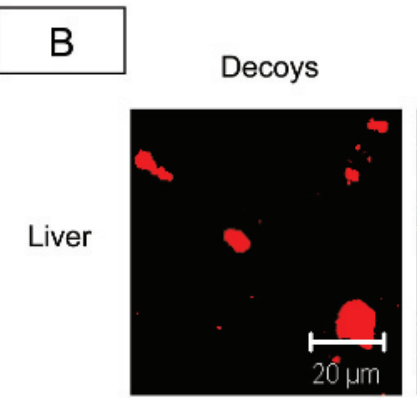

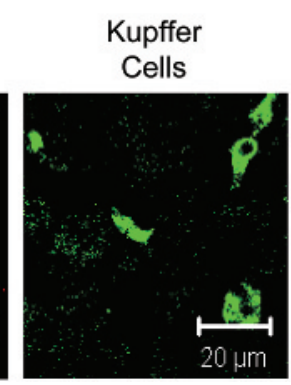

Nuclei

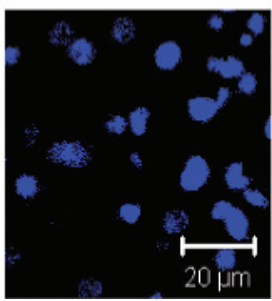

Overlay

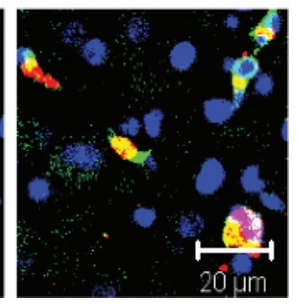

\section{MATERIALS AND METHODS}

Decoy oligodeoxynucleotides

NF- $\kappa$ B decoy oligodeoxynucleotides (5'-AGT TGA GGG GAC TTT CCC AGG C-3', 5'-GCC TGG GAA AGT CCC C CTC AAC

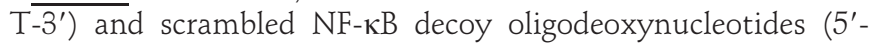
CCT TGT ACC ATT GTT AGC C-3', 5'-GGC TAA CAA TGG TAC AAG $G^{\prime}$ ) have been described elsewhere ${ }^{1617}$ and were purchased from Biomers, Ulm, Germany (biomers.net). Consensus sequences for p50 and p65 are underlined. For improved stability, all oligodeoxynucleotides were bridged with a phosphorothioate (PTO) backbone. ${ }^{18}$ For biodistribution studies, cis-decoy oligodeoxynucleotides were 5'-end-labelled with Alexa Fluor 488 fluorescent dye.

\section{Preparation of oligonucleotide-loaded gelatin nanoparticles}

Gelatin NPs were prepared as described previously by Zillies and Coester. ${ }^{19} \mathrm{NPs}$ were incubated with a solution containing NF- $\kappa \mathrm{B}$ decoy ODN, scrambled decoy ODN or Alexa Fluor 488-labelled $\mathrm{NF}-\kappa \mathrm{B}$ decoy ODN respectively. D-NP suspensions were freezedried and finally rehydrated under iso-osmotic conditions.

\section{Animals}

Male Sprague-Dawley rats (190-220 g) were purchased from Charles River laboratories (Sulzfeld, Germany). C57Bl/6 mice (20-25 g) were obtained from the animal facilities of the Institute of Experimental and Clinical Pharmacology and Toxicology of the University of Erlangen-Nuremberg,
Germany. They were maintained under controlled conditions $\left(22^{\circ} \mathrm{C}, 55 \%\right.$ humidity and $12 \mathrm{~h}$ day/night rhythm) and fed a standard laboratory chow.

\section{Experimental model for distribution studies in rats}

One millilitre of buffered NP solution containing $20 \mathrm{nmol}$ Alexa Fluor 488 5'-end-labelled NF-кB decoy oligonucleotides was injected into the portal vein and the organs were removed after 15 min. Livers were drained, rinsed free of blood with PBS and perfused with formalin $3 \%$ in PBS for protein fixation.

\section{Experimental model of NF-кB induction by LPS in rats}

One millilitre of either $20 \mathrm{nmol}$ NF- $\mathrm{BB}$ D-NP solution or scrambled D-NP solution was injected into the portal vein. After $15 \mathrm{~min}, 10 \mu \mathrm{g}$ of LPS $(50 \mu \mathrm{g} / \mathrm{ml}$ in PBS, Escherichia coli serotype 055:B05; Sigma, Munich, Germany) was applied to the portal vein. After $30 \mathrm{~min}$ blood and organs were collected.

\section{Mice model of fulminant hepatic failure}

GalN (Roth, Karlsruhe, Germany) was administered i.p. at $700 \mathrm{mg} / \mathrm{kg} 30 \mathrm{~min}$ prior to lipopolysaccharide (LPS, Salmonella abortus equi, i.p., $4.5 \mu \mathrm{g} / \mathrm{kg}$; Sigma-Aldrich Chemie, Taufkirchen, Germany). ${ }^{20}$ ConA (Sigma-Aldrich Chemie) was applied intravenously at $20 \mathrm{mg} / \mathrm{kg}$. Mice were treated (i.v.) with $150 \mu \mathrm{l}$ of a $3 \mathrm{nmol} \mathrm{NF- \kappa B} \mathrm{D-NPs} \mathrm{or} \mathrm{scrambled} \mathrm{D-NPs} \mathrm{per} \mathrm{mouse} 20$ min prior to GalN administration or $2 \mathrm{~h}$ prior to ConA administration. In another set of experiments NF- $\mathrm{B}$ NPs or scrambled 
Figure 2 Lipopolysaccharide (LPS)induced hepatic nuclear factor kappa B (NF- $\kappa \mathrm{B}$ ) activation/translocation and tumour necrosis factor $\alpha$ (TNF $\alpha$ ) mRNA expression is reduced by application of decoy oligonucleotide-loaded gelatin nanoparticles (D-NPs). (A) NF- $\kappa B$ binding activity was determined by electromobility shift assay (EMSA) of whole rat liver homogenates. One representative shift out of three is shown (upper panel). Lower panel shows the relative light unit (RLU) density. Controls were defined as $1.0(n=3$, mean with the SEM), ${ }^{*} p<0.05$ vs scr. D-NPs). (B) Rat liver slices stained with an antibody against $p 65$, shows $p 65$ distribution in Kupffer cells. Red: p65. Green: Kupffer cells. Blue: Hoechst staining of nuclei. (C) p65 staining of rat liver slices in lower magnification shows p65 distribution in hepatocytes (arrows). Red: p65. Green: Kupffer cells. Blue: Hoechst staining of nuclei. (D) TNF $\alpha$ mRNA expression of rat liver homogenates, controls were defined as $1.0(n \geqslant 5$, mean with the SEM, ${ }^{*} p<0.05$ vs scr. D-NPs). scr., scramble.

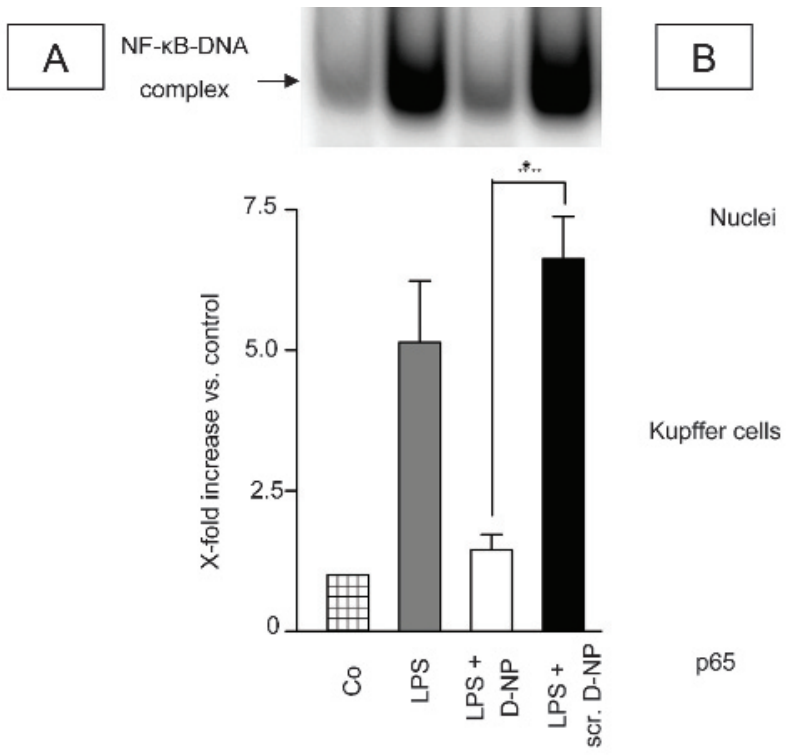

LPS + scr. D-NP

LPS + D-NP
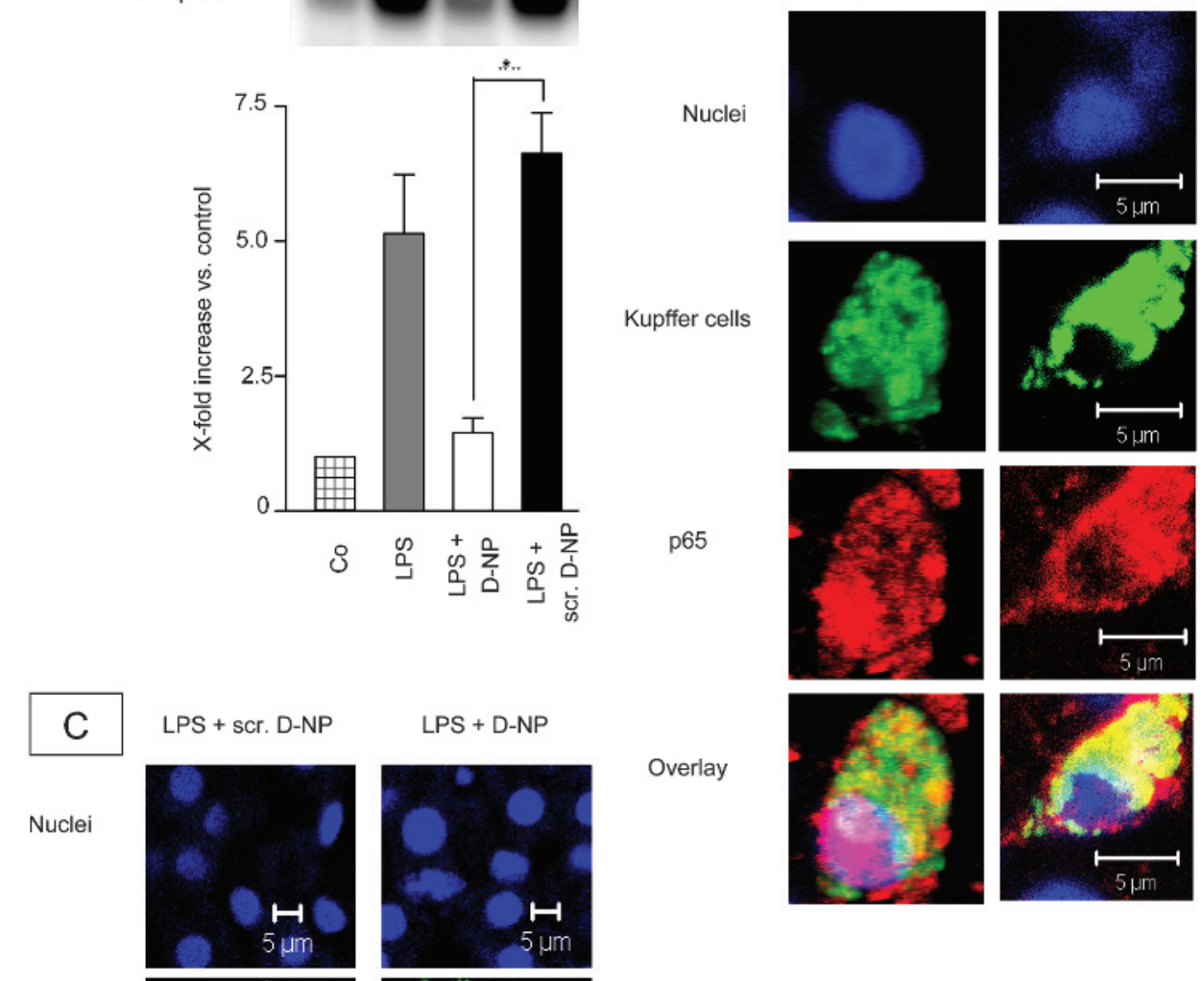

Overlay
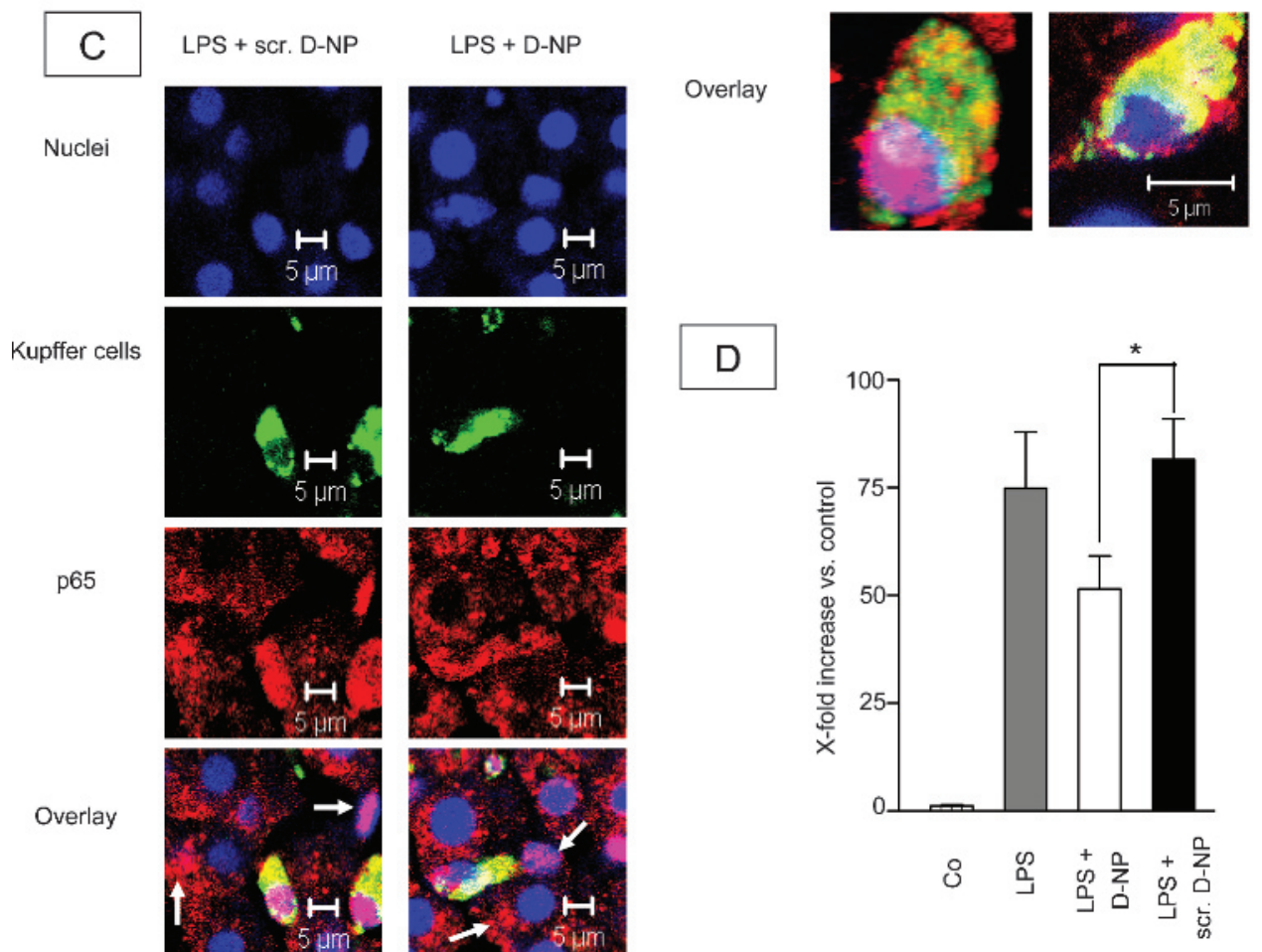

D-NPs were given $2 \mathrm{~h}$ after GalN/LPS injection. Twenty animals per group were used to determine survival rate.

\section{Rat model of partial warm hepatic ischaemia-reperfusion injury} The model used has been described by us before. ${ }^{21}$ The arterial and portal blood flow to the left lateral and median lobe of the liver was interrupted by applying an atraumatic clip, resulting in a $70 \%$ liver ischaemia. After $1 \mathrm{~h}$ of ischaemia, the blood supply was restored by removal of the clip and the reperfusion period was initiated. Blood samples were collected into heparinised tubes and animals were sacrificed after 2 and $24 \mathrm{~h}$ of reperfusion, respectively.

Fifteen minutes prior to initiation of ischaemia, $1.0 \mathrm{ml}$ of either $20 \mathrm{nmol}$ NF-kB D-NP solution or scrambled D-NP solution, respectively, were injected into the portal vein over a period of $5 \mathrm{~min}$.

\section{Histology of rat liver tissue}

Formalin-fixed, paraffin embedded rat liver samples were cut into $8 \mu \mathrm{m}$ slices. After deparaffinisation/rehydration, slices were stained using Coverplate chambers (Thermo Shandon, Frankfurt, Germany). For evaluation of NF-kB activation, sections were incubated with a rabbit polyclonal p65-antibody (1:50; RB-9034; Labvision, Fremont, California, USA) and a mouse anti-rat monoclonal CD 163-antibody (1:100; MCA342R; AbD Serotec, Duesseldorf, Germany) overnight at $4{ }^{\circ} \mathrm{C}$. The secondary antibodies Alexa Fluor 488 goat-anti-mouse and Alexa Fluor 546 goat-anti-rabbit (Invitrogen, Karlsruhe, 
Figure 3 Reduction of nuclear factor

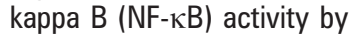
oligonucleotide-loaded gelatin nanoparticles (D-NPs) leads to a significant decrease in liver injury after $7 \mathrm{~h}$ D-galactosamine/lipopolysaccharide (GalN/LPS) challenge and correlates with extent of NF- $\kappa$ B activation in Kupffer cells (KCs). (A) Transaminase levels (aspartate transaminase (AST) and alanine aminotransferase (ALT)) of mice $(n=3$, mean with the SEM, ${ }^{*} p<0.05$ vs scr. DNPs). (B) Representative haematoxylineosin staining of mice liver sections.

(C) NF- $\kappa \mathrm{B}$ binding activity was determined by electromobility shift assay (EMSA) of whole mice liver homogenates. One representative shift (out of three) is shown and the mean relative light unit (RLU) density is shown on the right panel. Controls were defined as $1.0(n=3$, meanwith the SEM, ${ }^{*} \mathrm{p}<0.05$ vs scr. D-NPs). (D) Plasma level of tumour necrosis factor $\alpha(\mathrm{TNF} \alpha)$ and interleukin 6 (IL6) in mice were determined by enzyme-linked immunosorbent assay (ELISA) $(n=3$, mean with the SEM, ${ }^{*} p<0.05$ vs scr. D-NP). scr., scramble.
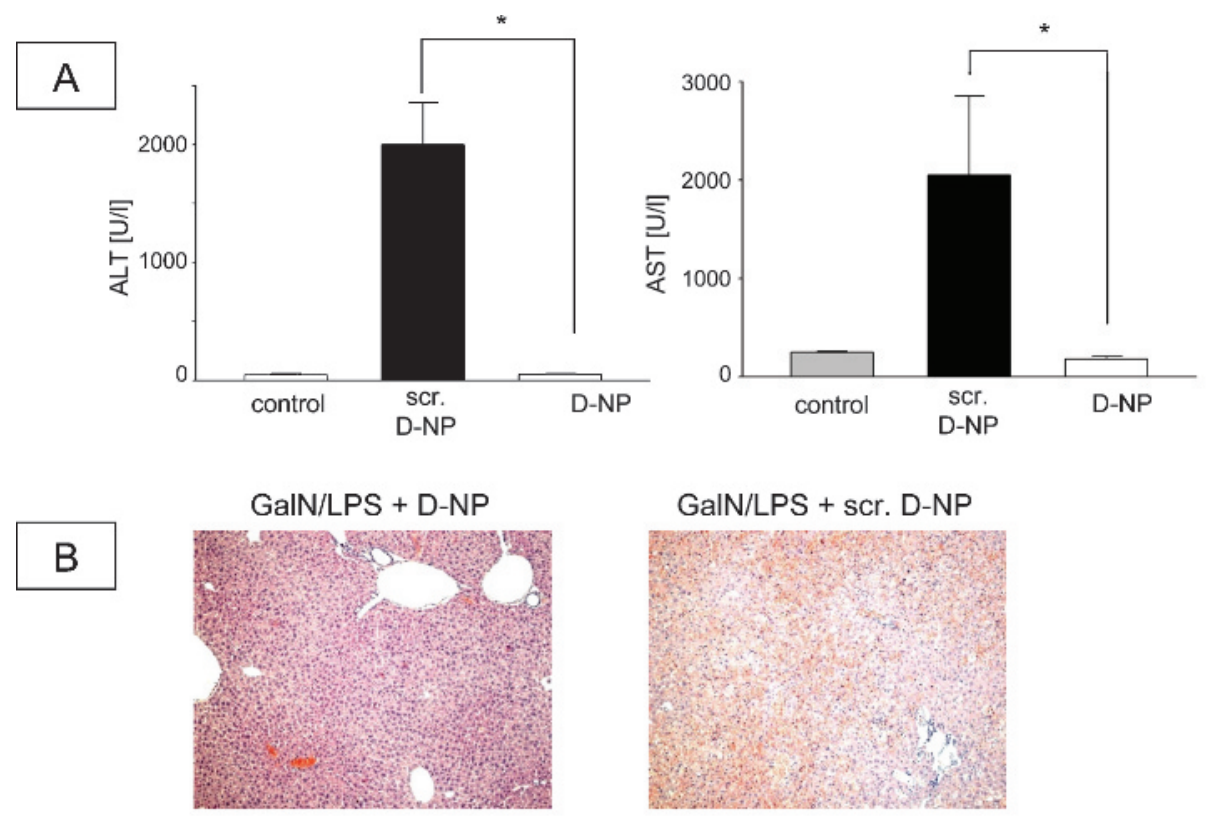

GalN/LPS + scr. D-NP
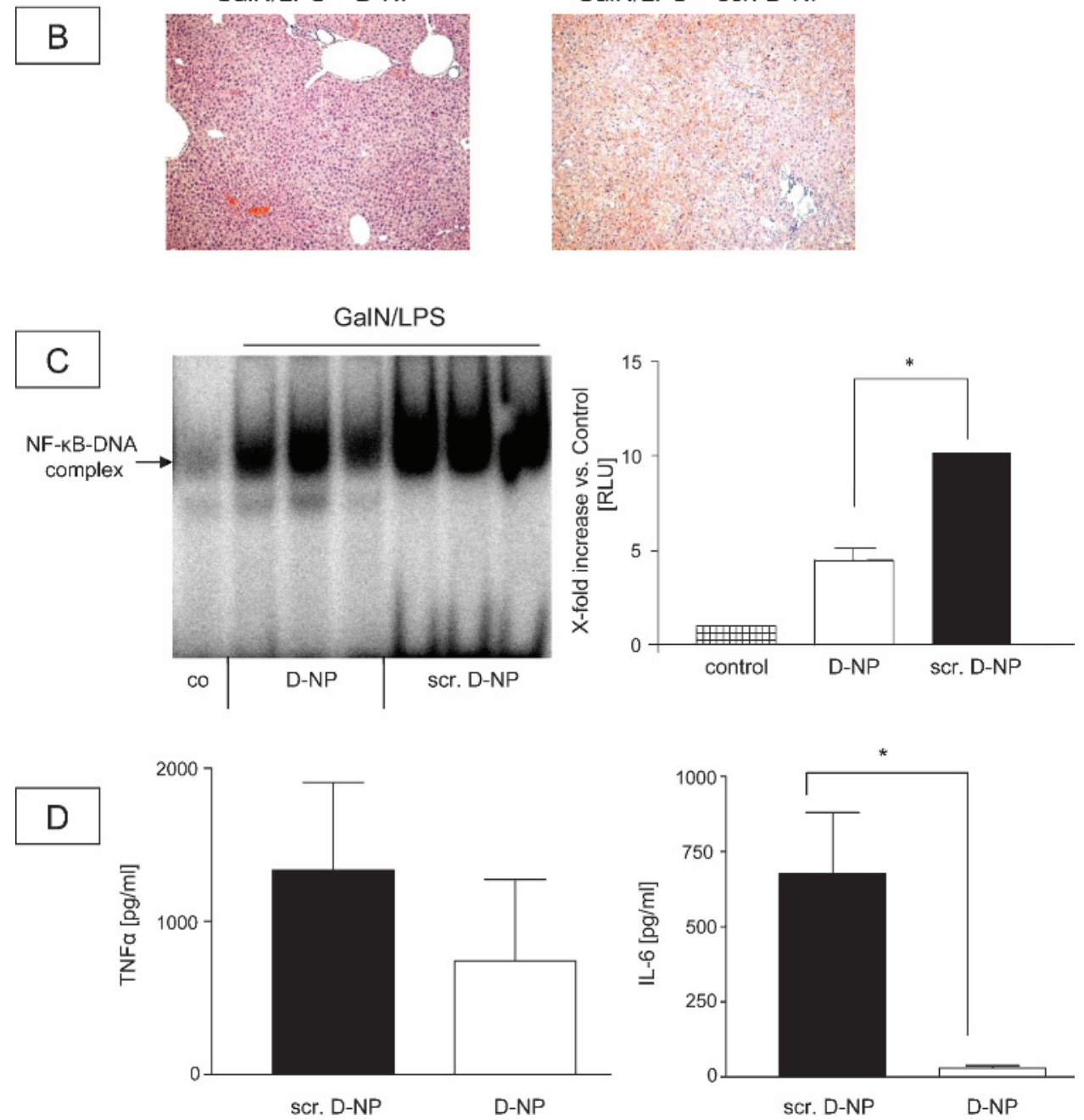

Germany) were applied for $45 \mathrm{~min}$, followed by staining of nuclei with Hoechst. Sections were mounted with PermaFluor Mounting Medium (Beckmann Coulter, Krefeld, Germany) and analysed by confocal laser scanning microscopy (CLSM) (Zeiss LSM 510 Meta CLSM; Carl Zeiss Microscope Systems, Jena, Germany). For evaluation of nanoparticle biodistribution, slices were treated accordingly (primary antibody mouse-anti-rat monoclonal CD 163, AbD Serotec, and secondary antibody Alexa Fluor 633 goat-anti-mouse, Invitrogen).

For evaluation of effects of decoy-nanoparticles on tissue damage, leucocyte infiltration and apoptosis after ischaemiareperfusion, formalin-fixed liver tissue samples were embedded in paraffin. Sections ( $5 \mu \mathrm{m}$ thickness) were cut and stained with haematoxylin and eosin (HE) using a standard protocol, with the terminal desoxynucleotide transferase-mediated dUTP nick end labelling (TUNEL) assay according to the manufacturer's instructions (ApopTag Peroxidase In Situ Apoptosis Detection Kit; Intergen, Purchase, New York, USA) and with naphthol ASD chloroacetate (ASD) in order to stain granulocytes.

The histological evaluations were done in a blinded fashion and a Leitz Laborlux S microscope (Leica Microsystems, Wetzlar, Germany) was used. In HE-stained sections the extent of necrosis (comprising loss of architecture, karyolysis and cell swelling) was expressed as a percentage. The number of ASDstained granulocytes in the periphery of the necrosis was counted in 10 high-power fields (HPFs). Apoptotic hepatocytes 
GalN/LPS

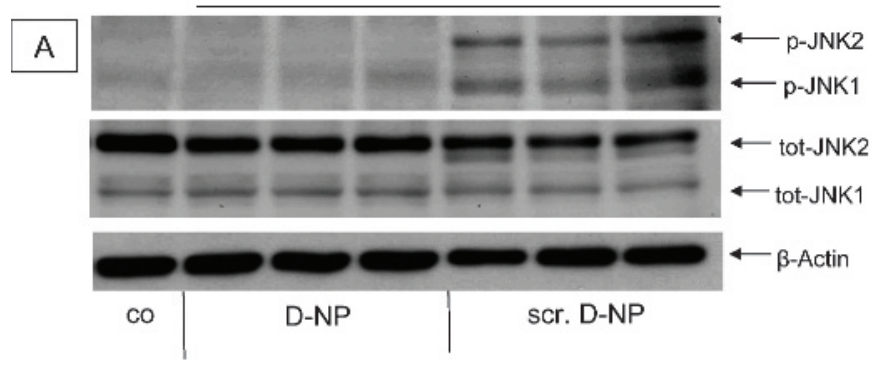

GaIN/LPS
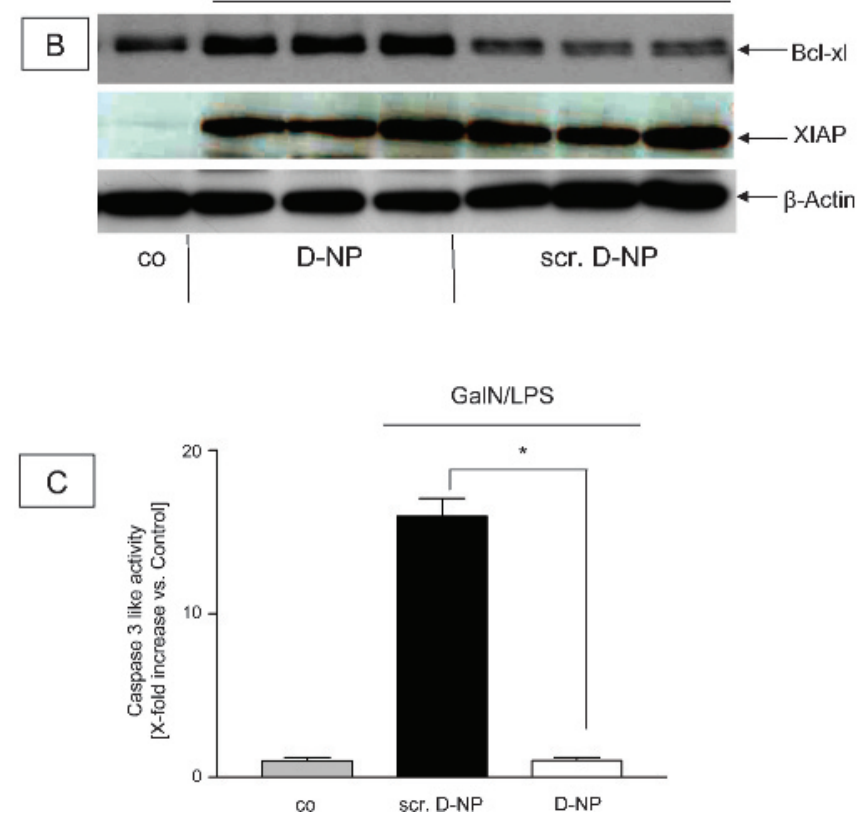

Figure 4 Pro-apoptotic processes are reduced in mice treated with oligonucleotide-loaded gelatin nanoparticles (D-NPs) before challenge with D-galactosamine/lipopolysaccharide (GaIN/LPS), whereas antiapoptotic protein expression is not diminished. (A) Hepatic expression of jun N-terminal kinase (JNK), pJNK and $\beta$-actin, respectively, by western blot analysis. One representative blot is shown. (B) Hepatic expression of $X$-linked inhibitor of apoptosis protein (XIAP), Bcl-xl and $\beta$-actin, respectively, by representative western blot analysis. (C) Caspase-3 like activity assay, controls were defined as $1.0(n=3$, mean with the SEM, ${ }^{*} \mathrm{p}<0.05$ vs scramble D-NPs).

were counted in 20 HPFs and were identified by staining with the TUNEL assay in combination with morphological features as chromatin condensation, forming of apoptotic bodies and cell shrinkage.

\section{DNA binding of NF-кB}

Electromobility shift assays (EMSAs) were performed as described previously. ${ }^{22}$ The consensus binding-sequence for NF- $\kappa B$ was 5'-AGT TGA GGG GAC TTT CCC AGG C-3' (Promega, Mannheim, Germany). Relative light unit (RLU) density was determined by autoradiography using the Cyclone Phosphor Imager (Perkin Elmer, Dreieich, Germany).

\section{Analysis of TNF $\alpha$ mRNA expression}

mRNA from liver tissue (25 mg) was isolated using the RNEasy Mini Kit (Qiagen, Hilden, Germany). Reverse transcription was carried out using the High Capacity cDNA Reverse
Transcription Kit. Real time PCR was conducted with the TaqMan Universal Master Mix Kit in a 7300 Real-Time PCR System (all from Applied Biosystems, Hamburg, Germany).

TNF $\alpha$ primers and probe (Rn99999017_m1) were also obtained from Applied Biosystems. Glyceraldehyde-3-phosphate dehydrogenase GAPDH) primers were designed using the Primer Express 2.0 software program. GAPDH forward primer: $5^{\prime}-\mathrm{GGG}$ AAG GTG AAG GTC GGA GT-3'; reverse primer: 5'-TCC ACT TTA CCA GAG TTA AAA GCA G-3'; probe: 5'-ACC AGG CGC CCA ATA CGA CCA A-3'.

Results were quantified based on the relative expression of the TNF $\alpha$ gene versus the housekeeping gene GAPDH using the mathematical model for relative quantification according to Pfaffl. ${ }^{23}$

\section{Measurement of transaminase activities}

Activities of serum aminotransferases (ALT and AST) were determined in heparinised serum $7 \mathrm{~h}$ after the induction of liver injury using an automated procedure.

\section{Haematoxylin-eosin staining of mice liver tissue}

Morphology of formalin-fixed, paraffin-embedded samples of the mice liver tissues was evaluated after H\&E-staining (30 s Mayer's Haemalum (Merck, Darmstadt, Germany); 3 s DEPCtreated water; $1 \mathrm{~min} 70 \%$ ethanol; $1 \mathrm{~min} 95 \%$ ethanol; $30 \mathrm{~s}$ eosin Y (Sigma Chemical, Deisenhofen, Germany); 1 min 95\% ethanol; 1 min 95\% ethanol; 1 min 100\% ethanol; air-dry for at least $10 \mathrm{~min}$ ).

\section{Cytokine measurement in murine plasma}

Sandwich ELISAs for murine plasma TNF $\alpha$ and IL6 were performed using flat-bottom high-binding polysterene microtitre plates (Greiner, Nurtingen, Germany). Antibodies were purchased from BD PharMingen Transduction Laboratories (Heidelberg, Germany). Streptavidin-peroxidase (Jackson Immuno Research, West Grove, Pennsylvania, USA) and the peroxidase chromogen tetramethylbenzidine (Boehringer Mannheim, Mannheim, Germany) were used according to the manufacturers' instructions.

\section{Cytokine measurement in rat plasma}

Blood samples were taken after $24 \mathrm{~h}$ of post-ischaemic reperfusion, heparinised and analysed with a Rat TNF $\alpha$ UltraSensitive ELISA Kit (BioSoure, Camarillo, California, USA).

\section{Western blot analysis}

Western blot analysis were performed as described previously. ${ }^{22}$ Proteins transferred to the membrane were identified by incubating with primary antibody (Bcl-xl; Santa Cruz, Heidelberg, Germany; XIAP, JNK, pJNK, Cell Signaling, Frankfurt, Germany; at $4^{\circ} \mathrm{C}$, over night), followed by incubation with a HRP-conjugated secondary antibody (goat anti rabbit, Dianova, Hamburg, Germany). The reactive bands have been visualised employing a chemiluminescent detection kit (ECL Plus, Amersham Pharmacia, Uppsala, Sweden). $\beta$-Actin was used as loading control (Millipore, Billerica, Massachusetts, USA).

\section{Measurement of caspase-3 like activity}

Liver tissue (20-60 mg) was homogenised (Potter S, B. Braun Biotech) in 200-600 $\mu$ lysis buffer $(25 \mathrm{mmol} / 1$ Hepes; $5 \mathrm{mmol} / \mathrm{l}$ $\mathrm{MgCl}_{2} ; 1 \mathrm{mmol} / 1$ EGTA; $\mathrm{pH}$ 7.5). Protein quantification was done by use of the Bradford assay. ${ }^{24}$ Extracts were incubated with Ac-DEVD-AFC, and the generation of AFC was determined by fluorescence measurement (excitation: $385 \mathrm{~nm}$; emission: $505 \mathrm{~nm}$ ). 


\section{Statistical analysis}

Animal experiments were performed using the number of animals as shown in the respective figure legends. Results are shown as mean with the SEM. Statistical analysis was performed using the GraphPad Prism 3.03 software. Significance $\left(^{*}\right)$ was calculated at a $95 \%$ confidence interval in comparison to the corresponding control experiments (nonparametic $t$ test).

\section{RESULTS}

\section{Persistent binding of NF-кB decoy oligonucleotides onto gelatin} nanoparticles of well-defined size diameter

Oligonucleotides (ODNs) were bound to gelatin NPs via ionic interactions between the negatively charged DNA and the positively modified surface of the NP. ${ }^{19}{ }^{25}$ A supernatant of decoy oligonucleotide-loaded gelatin NPs (D-NPs) suspension was analysed spectrophotometrically after various times to ensure persistent attachment of NF- $\mathrm{KB}$ decoy oligonucleotides. D-NPs displayed an average size of $262.5 \mathrm{~nm}$ with a polydispersity index of 0.105 , which indicates the homogenous size distribution of particles. ${ }^{19} 25$

\section{Intraportal injection of NF-кB gelatin nanoparticles results in predominant uptake by hepatic Kupffer cells}

Upon intravenous administration, NPs are generally cleared from the circulation through phagocytosis, preferentially by macrophages of the reticuloendothelial system (RES) concentrating mainly in liver and spleen. ${ }^{26}$ Due to their well-defined particle size distribution around $260 \mathrm{~nm}$, solid, inflexible gelatin NPs are too large to pass through the endothelial fenestrae (approx. $175 \mathrm{~nm}$ wide). Therefore, the uptake of gelatin NPs by hepatocytes should be almost impossible since the parenchyma is not accessible to these constructs.

Fifteen minutes after application of gelatin NPs loaded with Alexa Fluor 488-labelled decoy oligonucleotides, the majority of decoy oligonucleotides were distributed within the liver

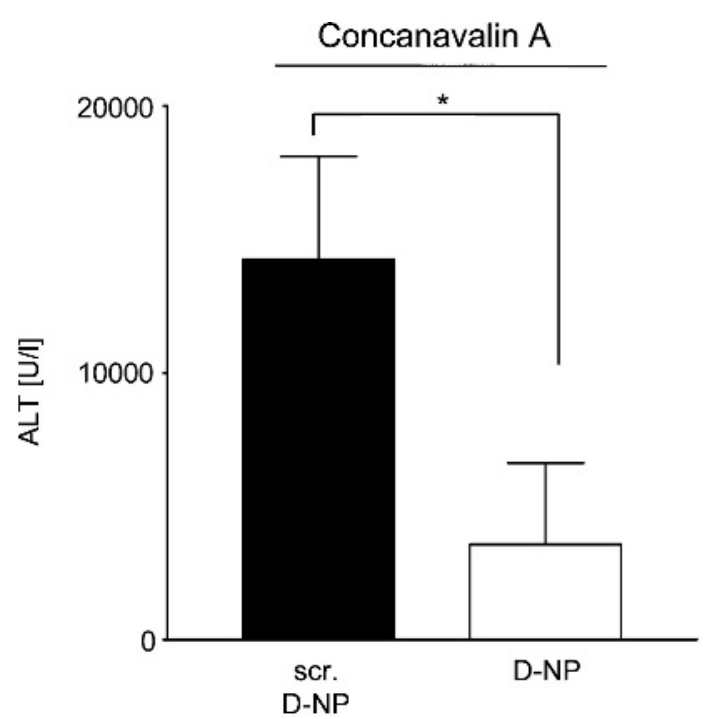

Figure 5 Role of the administration of nuclear factor kappa B (NF- $-\kappa B$ ) oligonucleotide-loaded gelatin nanoparticles (D-NPs) in liver injury after challenge with concanavalin A (ConA). Plasma levels of alanine aminotransferase (ALT) and aspartate transaminase (AST) of mice subjected to $7 \mathrm{~h}$ of ConA challenge ( $\mathrm{n}=3$, mean with the SEM, ${ }^{*} \mathrm{p}<0.05$ vs scramble D-NPs). referring to the number of positively stained cells. No detectable fluorescence was found in the brain, the kidney or the heart, and smaller quantities could be seen in lung and spleen (fig 1A). Figure $1 \mathrm{~B}$ displays the exact pattern of hepatic allocation, with a distinguished uptake of decoy oligonucleotides by KCs. Importantly, hepatocytes showed no incorporation of decoy oligonucleotides.

\section{NF-кB decoy oligonucleotide-loaded gelatin nanoparticles reduce NF- $\mathrm{KB}$ activation and translocation in Kupffer cells} EMSA analysis (fig 2A) showed significantly reduced LPS (30 min) evoked NF-кB DNA binding activity in liver tissue of D-NP-treated animals in comparison to the use of non-binding scrambled D-NP (1.45 (SD 0.47) and 6.62 (SD 1.31) x-fold increase, ie, reduction to $21.9 \%$ ). Moreover, nuclear translocation of $\mathrm{p} 65$, the most common subunit of NF- $\mathrm{KB}$ in the context of inflammation, was inhibited in $\mathrm{KC}$ by the administration of D-NPs (fig 2B). Whereas p65 was found within the nucleus after scrambled D-NP administration upon LPS challenge (left panel) the application of D-NP resulted in a cytoplasmatic retention of p65 (right panel). Nuclear p65 translocation in hepatocytes after 30 min of LPS challenge was very rare and was not affected by the application of D-NP (fig 2C, arrow).

To confirm that our D-NPs in fact inhibit NF- $\kappa \mathrm{B}$ driven transcription, we measured the expression of the TNF $\alpha$ gene. DNP markedly attenuated TNF $\alpha$ expression, whereas scrambled D-NPs had no effect (51.45 (SD 20.23) vs 81.52 (SD 21.09) x-fold increase, ie, reduction to $63.1 \%$; fig $2 \mathrm{D})$. The discrepancy between the extent of NF- $\kappa B$ inhibition and $\mathrm{TNF} \alpha$ reduction might reflect the fact that $\mathrm{TNF} \alpha$ underlies additional regulatory mechanisms besides the NF- $\kappa B$ system.

\section{GalN/LPS-induced liver injury is reduced by NF-кB oligonucleotide-loaded gelatin nanoparticles}

The effect of D-NPs was tested in a widely accepted model of fulminant hepatitis ie, in the model of GalN/LPS induced liver injury. NF- $\mathrm{BB}$ D-NPs were injected $20 \mathrm{~min}$ before GalN/LPS challenge. Liver injury was strongly reduced as determined by measurement of serum transaminase activities $7 \mathrm{~h}$ after GalN/ LPS administration (fig 3A). The fact that serum transaminase activities in NF- $\kappa B$ D-NP-treated animals after GalN/LPS administration are within the range of those of control animals suggests a lack of adverse effects of D-NPs to the liver.

Histological examination of liver tissue by $\mathrm{H} \& \mathrm{E}$ staining revealed a complete preservation in liver structure of NF- $\kappa \mathrm{B} D$ NP-treated animals (fig $3 \mathrm{~B}$ ). Furthermore, survival of animals was significantly increased by treatment with NF- $\mathrm{kB}$ D-NPs, scored $7 \mathrm{~h}$ after GalN/LPS challenge. Only one animal died in the D-NP-treated group $(\mathrm{n}=20)$ compared to eight animals in the group that received scrambled D-NPs $(n=20)$ prior to GalN/LPS stimulation $(p<0.05)$.

Interestingly, injection of NF- $\mathrm{BB} \mathrm{D}-\mathrm{NPs}$ even $2 \mathrm{~h}$ after the GalN/LPS administration seems to be beneficial with regard to transaminase measurements. Alanine aminotransferase (ALT) levels are significantly reduced in animals treated with NF- $\kappa B$ D-NPs as compared to the scrambled D-NP (1230 (SD 136) vs 3110 (SD 880) U/1) whereas aspartate transaminase (AST) levels only show a tendency of reduction in the NF- $\mathrm{B}$ D-NP group as compared to the scrambled D-NP group (1306 (SD 242) vs 1790 (SD 216) U/1).

As liver injury was diminished by NF- $\kappa B$ D-NPs, we next

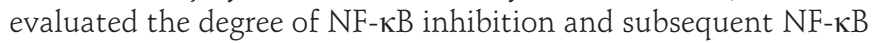
dependent transcription. EMSA analysis clearly showed a 
Figure 6 Impact of nuclear factor kappa $B(N F-\kappa B)$ inhibition on hepatic ischaemia-reperfusion injury (IRI). (A) $N F-\kappa B$ binding activity was determined by electromobility shift assay (EMSA) of whole rat liver homogenates after $1 \mathrm{~h}$ of warm ischaemia and $2 \mathrm{~h}$ of reperfusion. One representative shift is shown (upper panel). Lower panel shows the relative light unit (RLU) density. Controls were defined as $1.0(n=3$, mean with the SEM, ${ }^{*} \mathrm{p}<0.05$ vs scr. (scramble) D-NPs). (B) Transaminase levels of rats subjected to $1 \mathrm{~h}$ of ischaemia and $24 \mathrm{~h}$ of warm reperfusion ( $n=4$, mean with the SEM, ${ }^{*} p<0.05$ vs D-NPs). (C) Plasma tumour necrosis factor $\alpha$ (TNF $\alpha$ ) levels of rats subjected to $1 \mathrm{~h}$ of warm ischaemia and $24 \mathrm{~h}$ of reperfusion $(\mathrm{n}=4$, mean with the SEM). ALT, alanine aminotransferase; AST, aspartate transaminase;

D-NPs, oligonucleotide-loaded gelatin nanoparticles.
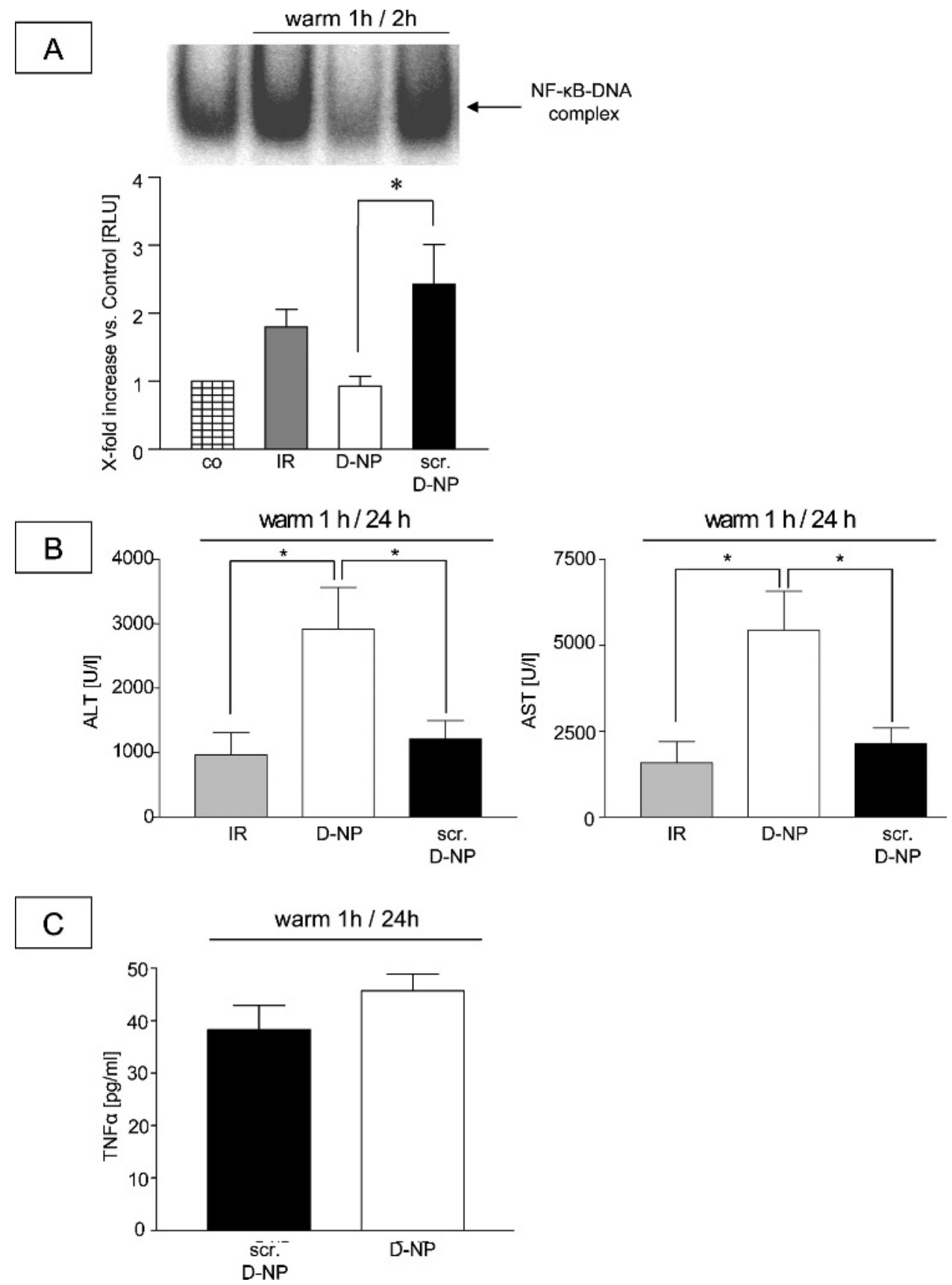

significant reduction in NF- $\mathrm{B}$ binding activity (4.48 (SD 1.13) vs 10.15 (SD 0.12) x-fold increase, ie, reduction to $44.1 \%$; fig 3C). The TNF $\alpha$ concentration in plasma was decreased and a pronounced reduction of interleukin 6 (IL6) plasma concentration was observed in animals, which had received $N F-\kappa B$ D-NPs (fig 3D).

Table 1 Histological analysis of liver tissue

\begin{tabular}{lcc}
\hline & $\begin{array}{l}\text { Decoy } \\
\text { nanoparticles }\end{array}$ & $\begin{array}{l}\text { Scrambled decoy } \\
\text { nanoparticles }\end{array}$ \\
\hline Necrosis (\% of area) & $63.75(17)$ & $40(4)$ \\
Leucocytes (per 10 high-power fields) & $394(56)$ & $260(116)$ \\
$\begin{array}{l}\text { TUNEL-positive cells (per 20 high-power } \\
\text { fields) }\end{array}$ & $11(1)$ & $12(2)$ \\
\hline
\end{tabular}

Data are mean (SEM).
Oligonucleotide-loaded gelatin nanoparticles attenuate proapoptotic liver signalling

The jun N-terminal kinase (JNK) plays a major role in the initiation of apoptotic pathways. Cross-talk between JNK and NF- $\kappa B$ has been postulated before. ${ }^{27}$ Most strikingly, inhibition of NF- $\kappa \mathrm{B}$ in $\mathrm{KCs}$ led to a reduction in JNK phosphorylation (fig 4A). In contrast, anti-apoptotic proteins such as X-linked inhibitor of apoptosis protein (XIAP) or Bcl-xl remained unchanged or even increased, respectively, as shown in fig 4B. In line with these effects caspase-3 activity in liver tissue was markedly decreased (fig 4C).

NF-кB oligonucleotide-loaded gelatin nanoparticles reduce injury in the concanavalin a model of hepatitis

For LPS challenge circulating TNF $\alpha$ is relevant, ${ }^{28}$ we therefore investigated the effects of D-NPs also in the ConA induced liver 
damage which is mainly mediated by cell-bound TNF $\alpha$. Interestingly NF- $\kappa \mathrm{B}$ D-NPs abrogated ConA-induced liver damage as well (fig 5).

\section{Impact of NF-кB oligonucleotide-loaded gelatin nanoparticles on hepatic ischaemia-reperfusion injury}

Hepatic ischaemia occurs during liver resections or transplantations. It is assumed that NF- $\kappa \mathrm{B}$ is activated in $\mathrm{KCs}$ soon upon reperfusion. As yet the actual role of $N F-\kappa B$ in $\mathrm{KCs}$ in ischaemia-reperfusion injury has not been addressed due to the lack of a suitable experimental tool. Hence, we investigated the impact of Kupffer cell targeted NF- $\mathrm{B}$ for the outcome of hepatic ischaemia-reperfusion injury by injecting D-NPs. Interestingly, an inhibition of NF- $\mathrm{BB}$ binding activity (fig 6A) led to an increase in liver injury after $24 \mathrm{~h}$ of reperfusion (fig $6 \mathrm{~B}$ ). Measurement of plasma TNF $\alpha$ indicated no difference in TNF $\alpha$ levels between the respective groups at $24 \mathrm{~h}$ reperfusion time (fig 6C). Furthermore, histological analysis as described under "materials and methods" revealed that ischaemia-reperfusion liver tissue of NF- $\mathrm{kB}$ D-NP-treated animals display a higher proportion of centrilobular coagulative necrosis, as well as stronger leucocyte infiltration, but no difference in TUNELpositive, apoptotic cells (table 1) compared to tissue of scrambled D-NP-treated animals. Apoptosis was exclusively evaluated in non-necrotic liver parenchyma because in the necrosis an intense artificial staining of the hepatic cytoplasm and nuclei occurred.

\section{DISCUSSION}

KCs play an important role in the pathogenesis of various inflammatory liver diseases. ${ }^{29}$ Inhibition of Kupffer cell activity by depletion with gadolinium chloride or clodronate liposomes reduces liver damage after ischaemia/reperfusion and ConA treatment, respectively. ${ }^{30-32}$ However, complete elimination and permanent inactivation of this important cell type from the liver is not a therapeutic option, since KCs are indispensable for immune function. ${ }^{33}$ Thus, strategies aiming at a reversible inhibition of $\mathrm{KC}$-driven inflammatory signalling such as NF- $\mathrm{kB}$ activation which might be clinically applicable are an important goal. Here we present a novel approach of selective KC targeting, which (1) might be of potential clinical use and (2) was appropriate to elucidate the role of NF- $\mathrm{BB}$ in $\mathrm{KCs}$ in various types of acute liver injury and ischaemiareperfusion injury.

In a model of fulminant liver failure (GaIN/LPS), a disease that is associated with many complications and high mortality in the clinic, administration of KC-targeting NF- $\mathrm{BB}$ D-NPs indeed resulted in a marked reduction of liver injury. Hepatocyte-specific NF- $\mathrm{B}$ inhibition is associated with a $\mathrm{TNF} \alpha$ induced increase of apoptosis and mortality. ${ }^{57}$ Kupffer cell selective downregulation of NF- $\mathrm{KB}$ by D-NPs, as shown here, leads to decreased inflammatory cytokine release as well as reduced apoptotic activity and tissue damage after GalN/LPS challenge. Along this line, phosphorylation and consecutively activation of the pro-apoptotic kinase JNK was blocked. This is in contrast to reports of NF- $\kappa \mathrm{B}$ inhibition leading to prolonged JNK activation. ${ }^{427}$ However, it has to be noted that these observations were made in hepatocytes. Obviously a selective inhibition of NF- $\mathrm{BB}$ in KCs leads to a reduction of parenchymal tissue injury in the liver, since the attenuation of TNF $\alpha$ production by KCs is most likely associated with lower JNK activity in hepatocytes and thus apoptotic activity as determined by caspase- 3 activity. Selective inhibition of NF- $\kappa B$ in
KCs did not impair XIAP expression, and even increased antiapoptotic Bcl-xl protein levels, both driven by NF- $\kappa \mathrm{B}$ activity, furthermore pointing to the fact that hepatocyte signalling was not immediately affected by D-NPs. In contrast, anti-apoptotic signalling in hepatocyte-specific NF- $\mathrm{BB}$ deficient mice presented by Beraza et $a l^{5}$ and Geisler et $a l^{7}$ is reduced, which might explain the worsening of liver injury in their models.

Recent data ${ }^{34}$ show a marked increase in liver damage after GalN/LPS challenge, if NF- $\kappa \mathrm{B}$ activity is reduced by the general NF- $\kappa B$ inhibitor pyrrolidene dithiocarbamate (PDTC), which blocks NF- $\kappa \mathrm{B}$ activation in both KCs and hepatocytes.

Hepatic ischaemia/reperfusion injury is another setting where inflammatory processes are thought to be responsible for tissue damage. KCs react fast after the onset of the reperfusion period and produce large amounts of reactive oxygen species (ROS), which subsequently trigger production and release of $N F-\kappa B$ driven cytokines like TNF $\alpha$ and IL6. ${ }^{35}$ Thus, a selective NF- $\kappa B$ inhibition in KCs should result in a similar beneficial outcome as seen in the model of GalN/LPS induced liver injury. For instance, Lentsch and colleagues showed recently that higher $N F-\kappa B$ levels in hepatocytes during ischaemia-reperfusion are linked with protection, while an increase of NF- $\mathrm{B}$ in KCs rather induces TNF $\alpha$ release and liver damage. ${ }^{36}$ Surprisingly, application of D-NPs and thus Kupffer cell specific NF- $\kappa$ B inhibition increased hepatic damage even further. This is in contrast to Matsui et al, who described less liver injury by treatment with PDTC in a model of $1 \mathrm{~h}$ warm ischaemia and $24 \mathrm{~h}$ of reperfusion. ${ }^{37}$ This again supports the notion that an overall inhibition of NF- $\kappa B$ with PDTC, in comparison to a selective NF- $\kappa \mathrm{B}$ blockade in $\mathrm{KCs}$, leads to opposite effects. Moreover, PDTC acts as a radical scavenger and exerts mainly antioxidative properties, ${ }^{38}$ which makes its use as selective NF- $\mathrm{B}$ inhibitor rather questionable.

In conclusion, we here present a novel tool to selectively inhibit $N F-\kappa B$ in KCs in vivo. We examined the impact of this selective NF- $\kappa B$ inhibition in the inflammatory models of GalN/LPS and ConA challenge, respectively, as well as in hepatic ischaemiareperfusion injury. It turned out that NF- $\mathrm{BB}$ in $\mathrm{KCs}$ seems to be indispensable for the protection of the hepatic parenchyma after ischaemia-reperfusion, while a selective inhibition in KCs after GalN/LPS or ConA challenge results in protection of the liver. Interestingly, the inflammatory impact caused by Kupffer celldependent NF-kB-activation during ischaemia-reperfusion seems not to be predominant for tissue injury. In contrast, selective inhibition in KCs leads to an increase in hepatic injury. Therefore, treatments aiming at NF- $\mathrm{BB}$ in the liver have to be used carefully, as effects specific to the type of cell and to the type of injury have to be taken into account.

Acknowledgements: The authors thank J Peliskova and B Hager for excellent technical assistance.

Funding: This work was supported by grants of the Deutsche Forschungsgemeinschaft (DFG, FOR 440).

Competing interests: None.

Ethics approval: All animals used in this study received human care in compliance with the "Principles of Laboratory Animal Care". The study was registered with the local animal welfare committee.

Provenance and peer review: Not commissioned; externally peer reviewed.

\section{REFERENCES}

1. Liu SF, Malik AB. NF-kappa B activation as a pathological mechanism of septic shock and inflammation. Am J Physiol Lung Cell Mol Physiol 2006;290:L622-45.

2. Marra F. Nuclear factor-kappaB inhibition and non-alcoholic steatohepatitis: inflammation as a target for therapy. Gut 2008;57:570-2. 
3. Wheeler MD, Yamashina S, Froh M, et al. Adenoviral gene delivery can inactivate Kupffer cells: role of oxidants in NF-kappaB activation and cytokine production. J Leukoc Biol 2001;69:622-30.

4. Liu H, Lo CR, Czaja MJ. NF-kappaB inhibition sensitizes hepatocytes to TNF-induced apoptosis through a sustained activation of JNK and c-Jun. Hepatology 2002;35:772-8.

5. Beraza N, Ludde T, Assmus U, et al. Hepatocyte-specific IKK gamma/NEMO expression determines the degree of liver injury. Gastroenterology 2007;132:2504-17.

6. Luedde T, Beraza N, Kotsikoris V, et al. Deletion of NEMO/KKgamma in liver parenchymal cells causes steatohepatitis and hepatocellular carcinoma. Cancer Cell 2007:11:119-32.

7. Geisler F, Algul H, Paxian S, et al. Genetic inactivation of RelA/p65 sensitizes adult mouse hepatocytes to TNF-induced apoptosis in vivo and in vitro. Gastroenterology 2007; 132:2489-503.

8. Luedde T, Assmus U, Wustefeld T, et al. Deletion of IKK2 in hepatocytes does not sensitize these cells to TNF-induced apoptosis but protects from ischemia/reperfusion injury. J Clin Invest 2005;115:849-59.

9. Gerondakis S, Grossmann M, Nakamura Y, et al. Genetic approaches in mice to understand Rel/NF-kappaB and lkappaB function: transgenics and knockouts. Oncogene 1999;18:6888-95.

10. Perkins ND. Post-translational modifications regulating the activity and function of the nuclear factor kappa B pathway. Oncogene 2006;25:6717-30.

11. Gallagher NJ, Young LS. Nuclear factor kappaB in liver disease. Gut 1999;45:170-1.

12. Suetsugu $\mathbf{H}$, limuro $Y$, Uehara $T$, et al. Nuclear factor $\{$ kappa $\}$ B inactivation in the rat liver ameliorates short term total warm ischaemia/reperfusion injury. Gut 2005; 54:835-42.

13. Romero EL, Morilla MJ, Regts J, et al. On the mechanism of hepatic transendothelial passage of large liposomes. FEBS Lett 1999;448:193-6.

14. Mann MJ, Dzau VJ. Therapeutic applications of transcription factor decoy oligonucleotides. J Clin Invest 2000;106:1071-5.

15. De Vry CG, Prasad S, Komuves L, et al. Non-viral delivery of nuclear factor-kappaB decoy ameliorates murine inflammatory bowel disease and restores tissue homeostasis. Gut 2007:56:524-33.

16. Kupatt C, Habazettl H, Goedecke A, et al. Tumor necrosis factor-alpha contributes to ischemia- and reperfusion-induced endothelial activation in isolated hearts. Circ Res 1999;84:392-400.

17. Romano MF, Lamberti A, Bisogni R, et al. Enhancement of cytosine arabinosideinduced apoptosis in human myeloblastic leukemia cells by NF-kappa B/Rel-specific decoy oligodeoxynucleotides. Gene Ther 2000;7:1234-7.

18. Lambert G, Fattal E, Couvreur P. Nanoparticulate systems for the delivery of antisense oligonucleotides. Adv Drug Deliv Rev 2001;47:99-112.

19. Zillies J, Coester C. Evaluating gelatin based nanoparticles as a carrier system for double stranded oligonucleotides. J Pharm Pharm Sci 2005; 7:17-21.

20. Keppler D, Lesch R, Reutter W, et al. Experimental hepatitis induced by Dgalactosamine. Exp Mol Pathol 1968;9:279-90.
21. Schauer RJ, Gerbes AL, Vonier D, et al. Glutathione protects the rat liver against reperfusion injury after prolonged warm ischemia. Ann Surg 2004;239:220-31.

22. Muller C, Dunschede F, Koch E, et al. Alpha-lipoic acid preconditioning reduces ischemia-reperfusion injury of the rat liver via the PI3-kinase/Akt pathway. Am J Physiol Gastrointest Liver Physiol 2003;285:G769-78.

23. Pfaffl MW. A new mathematical model for relative quantification in real-time RTPCR. Nucleic Acids Res 2001;29:e45.

24. Bradford MM. A rapid and sensitive method for the quantitation of microgram quantities of protein utilizing the principle of protein-dye binding. Anal Biochem 1976;72:248-54.

25. Zwiorek K, Kloeckner J, Wagner E, et al. Gelatin nanoparticles as a new and simple gene delivery system. J Pharm Pharm Sci 2005;7:22-8.

26. Kommareddy S, Amiji M. Biodistribution and pharmacokinetic analysis of longcirculating thiolated gelatin nanoparticles following systemic administration in breast cancer-bearing mice. J Pharm Sci 2006;96:397-407.

27. Wullaert A, Heyninck K, Beyaert R. Mechanisms of crosstalk between TNF-induced NFkappaB and JNK activation in hepatocytes. Biochem Pharmacol 2006;72:1090-101.

28. Maeda S, Chang L, Li ZW, et al. IKKbeta is required for prevention of apoptosis mediated by cell-bound but not by circulating TNFalpha. Immunity 2003;19:725-37.

29. Bilzer M, Roggel F, Gerbes AL. Role of Kupffer cells in host defense and liver disease. Liver Int 2006;26:1175-86.

30. Frankenberg MV, Weimann J, Fritz S, et al. Gadolinium chloride-induced improvement of postischemic hepatic perfusion after warm ischemia is associated with reduced hepatic endothelin secretion. Transp/ Int 2005;18:429-36.

31. Schumann J, Wolf D, Pahl A, et al. Importance of Kupffer cells for T-cell-dependent liver injury in mice. Am J Pathol 2000;157:1671-83.

32. Jang JH, Moritz W, Graf R, et al. Preconditioning with death ligands FasL and TNFalpha protects the cirrhotic mouse liver against ischaemic injury. Gut 2008;57:492-9.

33. Parker GA, Picut CA. Liver immunobiology. Toxicol Pathol 2005;33:52-62.

34. Lu JW, Wang H, Yan-Li J, et al. Differential effects of pyrrolidine dithiocarbamate on TNF-alpha-mediated liver injury in two different models of fulminant hepatitis. $J$ Hepatol 2008;48:442-52.

35. Jaeschke $\mathbf{H}$. Molecular mechanisms of hepatic ischemia-reperfusion injury and preconditioning. Am J Physiol Gastrointest Liver Physiol 2003;284:G15-26.

36. Kuboki S, Okaya T, Schuster R, et al. Hepatocyte NF-kappaB activation is hepatoprotective during ischemia-reperfusion injury and is augmented by ischemic hypothermia. Am J Physiol Gastrointest Liver Physiol 2007;292:G201-7.

37. Matsui N, Kasajima K, Hada M, et al. Inhibiton of NF-kappaB activation during ischemia reduces hepatic ischemia/reperfusion injury in rats. J Toxicol Sci 2005;30:103-10.

38. He HJ, Zhu TN, Xie Y, et al. Pyrrolidine dithiocarbamate inhibits interleukin-6 signaling through impaired STAT3 activation and association with transcriptional coactivators in hepatocytes. J Biol Chem 2006;281:31369-79. 


\section{GUT}

\section{A novel technique for selective NF- $\kappa B$ inhibition in Kupffer cells: contrary effects in fulminant hepatitis and ischaemia- reperfusion}

F Hoffmann, G Sass, J Zillies, et al.

Gut 2009 58: 1670-1678 originally published online May 25, 2009

doi: $10.1136 /$ gut.2008.165647

Updated information and services can be found at:

http://gut.bmj.com/content/58/12/1670.full.html

\section{These include:}

References This article cites 38 articles, 14 of which can be accessed free at: http://gut.bmj.com/content/58/12/1670.full.html\#ref-list-1

Article cited in:

http://gut.bmj.com/content/58/12/1670.full.html\#related-urls

Email alerting Receive free email alerts when new articles cite this article. Sign up in service the box at the top right corner of the online article.

Notes

To request permissions go to:

http://group.bmj.com/group/rights-licensing/permissions

To order reprints go to:

http://journals.bmj.com/cgi/reprintform

To subscribe to BMJ go to:

http://group.bmj.com/subscribe/ 